\title{
The Science-Practice Gap Among Recreation Managers With HR Responsibilities
}

Margaret D. Nowicki, (E-mail: mnowicki@ithaca.edu), Ithaca College Margaret Arnold, (E-mail: marnold@ithaca.edu), Ithaca College

\begin{abstract}
Researchers across management fields continue to recognize the importance of conducting research that matters to practitioners (e.g., Nowicki \& Rosse, 2001; Ford, Duncan, Bedeian, Ginter, Rousculp, \& Adams, 2003) yet continue to point out the schism that exists between needs of practitioners and research interests of academics. This paper presents the results of a research study conducted to explore the use and knowledge of sound HR hiring practices among leisure service professionals in NY State. Findings indicate that leisure service managers lack a sufficient amount of HR-specific knowledge to do their jobs soundly from a legal perspective.
\end{abstract}

\section{INTRODUCTION}

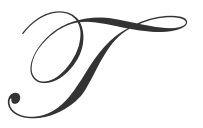

he leisure service profession is committed to enhancing the quality of life of the individuals and communities it serves. Managers of leisure services perform a variety of activities yet unfortunately, many managers within leisure services have not had sufficient training and development in human resource management (HRM) nor has the industry emphasized the importance of such knowledge. For example, the last textbook dedicated to HRM in leisure services was published two decades ago (Culkin \& Kirsch, 1986) and is clearly outdated - particularly as it relates to employment laws. Although some leisure services may be fortunate enough to have full-time HR specialists, the majority of recreation organizations (Recreation and Parks Departments, YMCAs, YWCAs, Boys and Girls Clubs, etc.) do not and therefore must rely on the recreation managers to have knowledge, skills and abilities to manage human resources. Unfortunately, many managers in leisure services will be the first to admit they feel ill-equipped in this area of their job description. To illustrate this point, one of us recently asked a group of recreation managers if they would hire a woman who is pregnant (and most qualified for the coaching position) even if they thought her pregnancy might interfere with the soccer season. Half of the managers said they would not hire her because she would not be able to fulfill her coaching responsibilities, yet the other half of the group indicated they must hire her because she was most qualified and they feared a potential lawsuit. Regrettably, none of the managers knew for sure what the Pregnancy Discrimination Act dictated for this type of situation. Interestingly, in 2005, the Equal Employment Opportunity Commission (EEOC) received 4,730 charges of pregnancy-based discrimination (eeoc.gov, 2006). The EEOC resolved each of the charges and recovered approximately $\$ 11.8$ million in monetary benefits for charging parties and other aggrieved individuals.

Moreover, anecdotally, our students report that unlawful questions are being asked of them during internship and job interviews. That is, leisure services managers are asking (unknowingly, one may presume) inappropriate and/or illegal questions during interviews. Some of these questions revolve around age, race, and ability to do the job due to gender. A relevant law in this situation is Title VII of the Civil Rights Act of 1964. The EEOC reports 55,976 charges filed under Title VII of the Civil Rights Act of 1964 in 2005 with monetary benefits of $\$ 146.0$ million (eeoc.gov, 2006). This personal observation is supported by research studies that have found managers in recreation organizations unknowingly participated in inequitable hiring and promotion practices (Allison, 1999). 
Researchers across management fields continue to recognize the importance of conducting research that matters to practitioners (e.g., Nowicki \& Rosse, 2001; Ford, Duncan, Bedeian, Ginter, Rousculp, \& Adams, 2003) yet continue to point out the schism that exists between needs of practitioners and research interests of academics. While management researchers assert that their work has little impact on management practice, in fact, examples exist of how managers have found and benefited from management research (Ford, et al., 2003). Suggestions based on research findings have also been made with regard to what exemplary research is in the eyes of management leaders, including senior executives and executive MBA's. In a research study conducted by Dossabhoy and Berger (2002), the authors report that these leaders believed great research begins with an explanation of managerial reality, with writing in short and crisp terms, and with an inclusion of explicit recommendations for a real problem. Further, they state that this research should not only be helpful but also improve the bottom line of a business. Consequently, we hope that by better understanding the HR-knowledge limitations of recreation managers, that we can contribute to closing the gap between science and practice.

\section{METHODOLOGY}

To gain a better understanding of the current practices used for managing human resources, we administered an online survey in February 2006 to members of the New York State Recreation and Park Society who were full-time middle or top level managers. The online survey addressed various areas of HRM such as job descriptions, affirmative action, orientation and training employees, and pre-employment inquires (i.e., employment laws). Respondent email addresses and job titles were retrieved from the Society mailing list. An email address list was generated for people with job titles including the words manager, director, or executive. Respondents received an invitation via email to participate, announcing the upcoming survey. Approximately 1 week later, a survey was emailed. Three weeks later, another survey was mailed to remind respondents to reply if they already had not. No compensation was offered. The respondents were promised a copy of the survey results if they desired them.

\section{RESULTS}

\section{Demographics Of Respondents}

One hundred fifty-four surveys were emailed out and the response rate was $28 \%$. Of those who responded, $95 \%$ were full-time professionals in leisure services. Among those professionals, $71 \%$ were employed in the public sector. A little more than half the respondents were 45 years old or younger, and 54\% identified themselves as female. All respondents identified their race as White. Thirty-one percent had completed some graduate work (another 31\% indicated they had completed their bachelor's degree). Two-thirds of respondents earned less than $\$ 60,000$ annually and half of the respondents had been in their current position 6 years or less. Half of the respondents had been in the recreation profession for 20 years or more while only one-third indicated that were certified as a park and recreation professional (CPRP).

\section{HR Related Responses: Training}

With regard to HRM training, over half (54\%) indicated they had no formal training; $27 \%$ indicated they had some college classes in this discipline; and 12\% indicated they had some daytime sessions (workshops, trainings, etc.). Despite that over half of all recreation managers reported they had no formal education or training in human resource management, they were responsible for employee selection processes (98\%), evaluating employees (95\%), disciplining and handling grievances (91\%), developing job analysis and/or job descriptions (88\%), recruiting employees (84\%), training and developing employees (77\%), providing professional development of employees $(72 \%)$, and administering orientation programs $(67 \%)$.

\section{HR Related Responses: Job Descriptions}

When asked how often you typically update job description for the jobs that you supervise, $35 \%$ of the respondents indicated they update the job descriptions about every one-to-three years. Just over one quarter of the respondents $(25.6 \%)$ indicated they updated the job descriptions about every three-to-five years. The remaining 
respondents indicated they update the job descriptions with each new hire (11\%), beyond five years (14\%) or it simply depends (11.6\%). Only $2.3 \%$ indicated they could not remember the last time the job descriptions had been updated. When asked about the order of tasks and duties listed within the job description, $46 \%$ indicated the list in the order in which the worker spends the greatest percentage of time. One-quarter of respondents indicated no specific order, and 15\% indicated the order was pre-established before their arrival. Only 5\% of respondents indicated they listed the job duties and responsibilities as they came to mind. When asked which of the following were included in the job descriptions for the workers that you supervise, respondents indicated the following: Primary duties and responsibilities (98\%), job title (93\%), summary of the job (84\%), person the worker reports to $(65 \%)$, rate of pay $(42 \%)$, and description of working conditions $(42 \%)$.

\section{HR Related Responses: Required Orientation and Training}

When asked what type of training you require your employees to complete, $93 \%$ required orientation to the job and its duties, and $80 \%$ indicated they require employees to complete an orientation to the organization. Other required trainings included sexual harassment (61\%), skill development (61\%), personal development (42\%), and diversity (40\%).

\section{HR Related Responses: Pre-Employment Inquiries}

Respondents were asked to check whether it is lawful, unlawful/undesirable, or depends to ask interviewees questions pertaining to a variety of subject areas such as age, sexual orientation, education, etc. More specifically, the table below illustrates these findings.

Table 1: Responses to the Lawfulness of Pre-employment Inquiries

\begin{tabular}{|l|c|c|c|}
\multicolumn{1}{c}{ Topic } & Uawful & $78 \%$ & Depends \\
\hline Age & $12 \%$ & $19 \%$ & $10 \%$ \\
\hline Arrest Record & $71 \%$ & $71 \%$ & $20 \%$ \\
\hline Disability & $9 \%$ & $81 \%$ & $5 \%$ \\
\hline Marital Status & $14 \%$ & $90 \%$ & $0 \%$ \\
\hline National Origin & $10 \%$ & $88 \%$ & $5 \%$ \\
\hline Race or Color & $7 \%$ & $95 \%$ & $3 \%$ \\
\hline Religion & $2 \%$ & $67 \%$ \\
\hline Sex & $29 \%$ & $97 \%$ & $3 \%$ \\
\hline Sexual Orientation & $0 \%$ & $57 \%$ & $12 \%$ \\
\hline Birthplace & $31 \%$ & $7 \%$ & $5 \%$ \\
\hline Citizenship & $88 \%$ & $5 \%$ & $10 \%$ \\
\hline Drivers License & $85 \%$ & $2 \%$ & $6 \%$ \\
\hline Education/ Experience & $92 \%$ & $7 \%$ & $17 \%$ \\
\hline Military Experience & $76 \%$ & $39 \%$ & $27 \%$ \\
\hline Provide Photo & $34 \%$ & $15 \%$ & $27 \%$ \\
\hline Organizational Membership & $58 \%$ & $10 \%$ & $11 \%$ \\
\hline Who to Notify in Emergency & $79 \%$ & & \\
\hline
\end{tabular}

\section{DISCUSSION}

Not every manager within leisure services can be an expert in all fields including human resources, and our research suggests that reality. Nevertheless, it does make great business sense to consider sound advice regarding HR practices, if only to help avoid legal issues. Based upon our research findings, we share some of the most important guidelines to follow to help in managing in a more legally sound way. 


\section{Job Descriptions}

First, when completing a job description, list duties and responsibilities in order of percentage of time spent doing those things (highest first and in descending order). The duties and responsibilities that take the greatest percentage of time and hence, the knowledge, skills, and abilities (KSA's) required to fulfill those duties should be sought after in applicants. Hire the most qualified applicant based on the ability to fulfill the "essential job duties" (USEEOC, 2006). Second, update job descriptions at least yearly, or when a new job is created, or when the job has changed (whichever happens first). In order to do so, ask the employees who have the job to keep a log of what they do and how they spend their time, reminding them to record time or percentage of time. Do not assume employees not in the job know how other employees spend all their time each day. Third, regarding content of the job description, make sure the job title, specification of whether the job is exempt or non-exempt with regard to the Fair Labor Standards Act (FLSA), date of the job description, job summary, list of primary duties and responsibilities, description of working conditions (including extreme conditions), as well as name of the person to whom this employee reports are included. Including more factual information (rather than less) enables the person hiring employees to select the most qualified applicant.

\section{Required Orientation \& Training}

Understand that training employees with regard to sexual harassment and diversity makes great business sense. Numerous court decisions and guidelines issued by the EEOC have made sexual harassment training a mustdo for employers (Martucci \& Lu, 2005). With regard to diversity training, research suggests that organizations that create an environment of inclusion through diversity training also create a safer working environment, foster employee engagement, commitment, and pride, and see a positive impact on customer satisfaction and benefits in terms of financial performance (Pollitt, 2005). Easier said than done! Help create, with other leaders in the organization, a statement with regard to sexual harassment and one with regard to diversity. In them, identify what constitutes sexual harassment and what constitutes respect for diversity. Training employees with regard to what these issues mean to the organization, examples of appropriate behaviors and comments, and examples of what is not tolerated (and the resulting consequences) and then holding all employees accountable helps reduce circumstances which might result in litigation against your organization. That said, this training will not work or last, that is, employees will not take it seriously, if leaders at the top of the organization chart don't espouse the values.

\section{Pre-Employment Inquiries}

Do not ask questions that are directly discriminatory or even potentially discriminatory. That is, ask jobspecific questions only (think "job description"). In effort to not discriminate against people with regard to race, religion, sex, national origin, against pregnant women, against people with disabilities, nor against individuals who are gay or lesbian-- if questions are not directly related to the job at hand - do not ask them! While there are gray areas to many of these subject areas, internet resources such as guidance from the University of Washington website (http://www.stat.washington.edu/www/jobs/questions/) may help guide appropriate inquiry. For example, when it is directly related to the job (e.g., a person must be 18 years old out our facility in order to lifeguard) it is lawful to ask an interviewee if they are 18 years of age or older and if not, to state their age. It is not desirable to ask how old they are when it is not related to the ability or legal requirement for the job. Another example: It is not lawful to ask an applicant if they go to church, assuming that if they go to church, they can't work weekends. Certainly, if it is necessary to know if the applicant can work on the weekends, for that is the job requirement, ask, "We need an employee to cover all weekends, both Saturdays and Sundays from 9am to $6 \mathrm{pm}$. Do you have any obligations that will prevent you from doing this?" This question asks nothing about religion, just the job-related details-Are you able to work on weekends or not? Clearly, even just with these two examples, one can readily understand the complexities of guidelines for pre-employment inquiries. 


\section{CONCLUSION}

Since many managers in leisure services have not been educated and specifically trained for managing human resources, it may behoove them to visit the Equal Employment Opportunity Commission website at www.eeoc.gov to gain a better understanding of federal EEO laws, discriminatory practices, and employers and other entities covered by the EEO laws. Very rarely do we find managers of leisure services with expertise in HRM, specifically with regard to the employment laws. Each year, millions of dollars are tied up in lawsuits that could have easily been prevented had the manager sought guidance of an expert in HRM. In leisure services, managers don't profess to have all the answers to HRM, but they do owe it to the profession to ask questions so that they can become more educated in an area outside their expertise.

\section{Bibliography}

1. Allison, M. (1999). Organizational barriers to diversity in the workplace. Journal of Leisure Research, 31 (1), 78-101.

2. Culkin, D., \& Kirsch, S. (1986). Managing Human Resources in Recreation,Parks, and Leisure Services. Macmillan Publishing Co., New York.

3. Dossabhoy, N. \& Berger, P. (2002). Business school research: Bridging the gap between producers and consumers. Omega, 30(4), 301-314.

4. $\quad$ EEOC (2006). Pregnancy Discrimination Charges EEOC \& FEPAs Combined: FY 1992- FY 2005. http://www.eeoc.gov/stats/pregnanc.html. (retrieved 12/31/06)

5. $\quad$ EEOC (2006). Title VII of the Civil Rights Act of 1964 Charges, FY 1992- FY 2005 http://www.eeoc.gov/stats/vii.html. (retrieved 12/31/06)

6. Ford, E., Duncan, W., Bedeian, A., Ginter, P., Rousculp, M., \& Adams, A. (2003). Mitigating risks, visible hands, inevitable disasters, and soft variables: Management research that matters to managers. Academy of Management Executive, 17(1),46-60.

7. Martucci, W. \& Lu, Z. (2005). Sexual-harassment training: The wave of the future in state legislative efforts. Employment Relations Today, 32(2), 87-96.

8. Mohrman, S., Gibson, C., \& Mohrman, A. (2001). Doing research that is useful to practice: A model and empirical exploration. Academy of Management Journal, 44(2), 357-375.

9. Nowicki, M., \& Rosse, J. (2002). Managers' views of how to hire: Building bridges between science and practice. Journal of Business and Psychology, 17(2), 157-170.

10. Pollitt, D. (2005). Diversity is about more than observing the letter of the law. Human Resource Management International Digest, 13(4), 37-40.

11. University of Washington (2006). University of Washington statistics: Illegal questions. http://www.stat.washington.edu/www/jobs/questions/. (retrieved 12/31/06).

12. U.S. Equal Employment Opportunity Commission. (2006). Americans with Disabilities Act Questions and Answers. http://www.ada.gov/q\%26aeng02.htm (revised June 27). (retrived 12/31/06). 
NOTES 